\title{
Tema Gerador e a Relação Universidade-Escola: Percepções de Professoras de Ciências de uma Escola Pública em Ilhéus- $\mathbf{B A}^{\mathbf{1}}$
}

(Generative Theme and the Interaction University-School: Perceptions of Science Teachers of a Public School in Ilhéus-BA)

\section{POLLIANE SANTOS DE SOUSA ${ }^{1}$, ANA PAULA SOLINO BASTOS ${ }^{2}$, PRISCILA SILVA DE FIGUEIREDO ${ }^{3}$ e SIMONI TORMÖHLEN GEHLEN ${ }^{4}$}

\author{
${ }^{1}$ Universidade Federal de Santa Catarina (polliane.sds@gmail.com) \\ ${ }^{2}$ Universidade de São Paulo (ana.solino@gmail.com) \\ ${ }^{3}$ Universidade Estadual do Sudoeste da Bahia (psfigueiredo2@gmail.com) \\ ${ }^{4}$ Universidade Estadual de Santa Cruz (stgehlen@gmail.com)
}

\begin{abstract}
Resumo. Investigam-se contribuições e dificuldades identificadas por professoras da Educação Básica na construção de atividades didático-pedagógicas, a partir de um Tema Gerador, em conjunto com um grupo de estudos da Universidade Estadual de Santa Cruz. Os procedimentos metodológicos incluem a construção de um diário reflexivo e a realização de entrevistas semiestruturadas, junto com as professoras. A análise das informações foi orientada pela Análise Textual Discursiva, que permitiu a construção das categorias: a) Condições para o planejamento e implementação da proposta baseada em Tema Gerador e b) Parceria universidade-escola. Entre os resultados, destacam-se as seguintes dificuldades das professoras: falta de tempo, seja para o planejamento em conjunto ou para a implementação de atividades em sala de aula e a necessidade de adaptar as atividades baseadas em temas para diferentes turmas. Quanto às contribuições, destacam-se a parceria com o grupo de estudos para aproximação dos resultados da pesquisa em Ensino de Ciências da Educação Básica e a abordagem de Temas Geradores para a formação dos educandos.

Abstract. The present study investigates the contributions and difficulties encountered by teachers of the elementary school, during the construction of didactic-pedagogic activities based in a Generative Theme in conjunct with a study group of the Universidade Estadual de Santa Cruz. The methodological procedures include the construction of a reflexive diary and a semi-structured interview conducted with the teachers. The analysis of information was guided by Discursive Textual Analysis, which allowed the construction of categories: a) Conditions to planning and implementation of the proposal based in Generative Theme and b) Partnership university-school. Among the results, it is emphasized the following difficulties of the teachers: lack of the time either for the planning in group or for the implementation of the activities in classroom and the need of the adaptation the activities based in theme for different students. Among the contributions, it is emphasized the partnership with study group to approximation of the results by research in Science Teaching of the elementary school and the approach of the Generative Theme for the students formation.
\end{abstract}

Palavras-chave: ensino de ciências/física, currículo, abordagem temática freireana, práxis curricular via tema gerador

Keyword: teaching of science/physics, curriculum, freirean thematic approach, curriculum praxis via theme generator

\section{Introdução}

No contexto do Ensino de Ciências, pesquisadores têm proposto atividades didático-pedagógicas que contribuam com a ressignificação do currículo escolar. Dentre elas, estão aquelas que propõem a reorganização curricular com base em temas, a exemplo da Abordagem Temática Freireana (DELIZOICOV et al., 2011) e da Práxis

1 Uma versão preliminar deste estudo foi apresentada no XV Encontro de Pesquisa em Ensino de Física, 2014. Apoio Fapesb. 
Curricular via Tema Gerador (SILVA, 2004), ambas fundamentadas nas ideias de Paulo Freire.

Estudos têm sinalizado que o desenvolvimento de propostas desta natureza pode constituir espaço para o repensar da prática educativa, agregando elementos da formação continuada de professores, bem como contribuir com a socialização dos resultados das pesquisas em Ensino de Ciências e com a articulação entre universidade e escola (HALMENSCHLAGER et al., 2011; HALMENSCHLAGER et al., 2013).

Por outro lado, há necessidade de maiores implementações e aproximações com o contexto escolar mediadas pela participação do professor da escola, visto que trabalhos desenvolvidos sem considerar tais elementos têm relativamente pouca influência na implantação de propostas que almejam mudanças (DELIZOICOV, 2005). Além disso, Stuani (2010) discute que propostas que sugerem uma mudança na lógica do ensino descritivo e transmissivo para uma lógica de participação, tal como proposto pela Abordagem Temática Freireana e pela Práxis Curicular via Tema Gerador, remetem para a necessidade de uma formação permanente, que "envolve olhar para o docente não como um sujeito passivo, mas como criador e transformador de suas práticas, pela reflexão constante de sua ação.” (STUANI, 2010, p. 42).

Embora existam iniciativas voltadas para a reorientação curricular com base em temas pautados nos pressupostos freireanos tanto com licenciandos (DEMARTINI; SILVA, 2013; TAVARES et al., 2013; SOUSA et al., 2014), quanto com professores da educação básica (CARAMELLO et al., 2014; GIACOMINI; MUENCHEN, 2015), há necessidade de ampliar os estudos voltados para às relações entre esse processo e a formação de professores (HALMENSCHLAGER et al., 2011).

Assim, objetiva-se investigar, no contexto da formação docente, contribuições e dificuldades sinalizadas por duas professoras de Ciências de uma escola pública do município de Ilhéus-BA durante o processo de investigação de um Tema Gerador, realizado em parceria com um grupo de estudos pertencente à Universidade Estadual de Santa Cruz.

\section{Relações entre a abordagem temática freireana e a práxis curricular via tema gerador}

Fundamentadas nas ideias de Paulo Freire, a Abordagem Temática Freireana (DELIZOICOV et al., 2011) e a Práxis Curricular via Tema Gerador (SILVA, 2004) propõem a organização do programa escolar a partir de um Tema Gerador, o qual 
apresenta em sua essência situações-limites ${ }^{2}$ contidas na realidade existencial dos educandos, sendo selecionado por meio do processo denominado de Investigação Temática (FREIRE, 1987). Embora essas propostas estejam em sintonia com a concepção de currículo crítico, na qual a discussão da realidade social é privilegiada, tendo em vista a ação coletiva em frente aos problemas que dela emergem (LIBÂNEO, 1990), elas diferem entre si em alguns aspectos, tal como na organização das etapas envolvidas na Investigação Temática.

Na Abordagem Abordagem Temática Freireana (DELIZOICOV et al., 2011) o processo de Investigação Temática é organizado em cinco etapas: $1^{\mathrm{a}}$ etapa - levantamento preliminar: reconhecimento da comunidade local; $2^{\text {a }}$ etapa - análise e escolha das contradições sociais identificadas junto à comunidade e elaboração das codificações; $3^{\text {a }}$ etapa - discussão das codificações no contexto dos círculos de investigação temática e obtenção do Tema Gerador; $4^{\mathrm{a}}$ etapa - elaboração do programa e do planejamento de ensino; $5^{\text {a }}$ etapa - desenvolvimento do programa em sala de aula.

O processo de obtenção do Tema Gerador proposto pela Práxis Curricular via Tema Gerador (SILVA, 2004), por sua vez, é organizado em cinco momentos, quais sejam: i) Desvelamento do real pedagógico a partir das necessidades imanentes da prática problematização da prática pedagógica vigente na escola;

ii) Resgate de falas significativas constituindo sentido à prática: elegendo temas/contratemas geradores - busca pelas situações-limite a partir das falas dos moradores da comunidade e problematização das mesmas junto aos educandos para obtenção do Tema Gerador;

iii) Contextualização e percurso do diálogo entre falas e concepções da realidade local: rede temática e questões geradoras - construção de uma Rede Temática relacionando a visão de mundo dos educandos expressa no Tema Gerador com a visão dos educadores sintetizada pelo Contratema e identificação dos conceitos unificadores ${ }^{3}$ presentes na rede que podem ser privilegiados no planejamento;

\footnotetext{
${ }^{2}$ As quais, baseando-se nos estudos do Prof. Álvaro Vieira Pinto, são compreendidas por Freire (1987) como determinantes históricas, situações percebidas pelos indivíduos como determinísticas e sobre as quais eles não possuem uma visão crítica.

3 Podem ser compreendidos como conceitos supradisciplinares que minimizam a fragmentação dos conteúdos, são eles: i) Transformações: da matéria no espaço e no tempo; ii) Regularidades: que agrupam transformações da matéria segundo as suas características; iii) Energia: que instrumentaliza transformações e conservações e apresenta a degradação; iv) Escalas: que enquadram os eventos em dimensões e devem ser consideradas na avaliação dos domínios de validade de determinada teoria (ANGOTTI, 1991).
} 
iv) Planejamento e organização pedagógica da prática crítica - construção de questões geradoras gerais e específicas, elaboração e implementação do programa escolar;

v) Reorganização coletiva da escola a partir do fazer pedagógico - reorganização das atividades propostas com base na perspectiva dialógica adotada.

Ainda que as propostas apresentem algumas diferenças nas etapas do processo de Investigação Temática, o estudo de Torres (2010), ao analisar as relações entre elas, explica que ambas foram complementando o processo proposto por Paulo Freire, aproximando-as do contexto escolar.

Discussões semelhantes as de Torres (2010) foram apresentadas em um trabalho anterior realizado pelo Grupo de Estudos sobre Abordagem Temática no Ensino de Ciências (GEATEC) (SOUSA et al., 2014), que analisou o processo de obtenção de um Tema Gerador mediante a articulação entre as etapas de Investigação Temática da Abordagem Temática Freireana e da Práxis Curricular via Tema Gerador. O trabalho revelou que, de modo complementar, as etapas de Investigação Temática da Abordagem Temática Freireana e da Práxis Curricular via Tema Gerador se intercalaram formando uma rede de significados que auxiliaram a obtenção do tema e a organização da prática pedagógica. Com isso, Sousa et al. (2014) destacam o caráter dinâmico do processo de Investigação Temática, cujas etapas não devem ser compreendidas como estanques, mas como recomendações que podem se adequar ao contexto educacional em pauta, desde que os fundamentos teórico-metodológicos da perspectiva freireana sejam preservados.

\section{Aspectos metodológicos}

Com base nas relações estabelecidas entre a Abordagem Temática Freireana e a Práxis Curricular via Tema Gerador e tendo como referência a articulação das etapas de investigação do tema destas perspectivas, foi construído um conjunto de atividades didático-pedagógicas para a disciplina de Ciências do $6^{\circ}$ ano do Ensino Fundamental II.

A construção das atividades ocorreu mediante a parceria entre três professoras de Ciências de uma escola municipal localizada no Bairro Banco da Vitória em IlhéusBA e o GEATEC ${ }^{4}$ da Universidade Estadual de Santa Cruz (UESC).

A dinâmica de elaboração das atividades foi realizada por meio de reuniões semanais de planejamento do GEATEC e reuniões semanais junto com as professoras

\footnotetext{
${ }^{4}$ No período de desenvolvimento da pesquisa o grupo era composto por uma licencianda em Física, uma pedagoga com mestrado na área de Ensino de Ciências, uma bióloga com mestrado em Ensino, História e Filosofia das Ciências, e uma professora universitária com formação em Ensino de Física, coordenadora do grupo.
} 
para discussão da proposta no período de Março a Julho de 2013. Os encontros semanais com as professoras aconteciam na escola durante o horário das suas Atividades Complementares ${ }^{5}$, que correspondiam, aproximadamente, uma hora e trinta minutos. Já os encontros do GEATEC, ocorriam na própria UESC, precedendo as atividades na escola.

A opção pela construção da proposta didático-pedagógica, nesse contexto, está relacionada ao fato de que, embora a comunidade do Banco da Vitória fique localizada na rodovia entre a cidade de Ilhéus e a UESC, trajeto diário de boa parte dos universitários e funcionários da UESC, há indicativos de que existe uma carência no desenvolvimento de projetos da universidade neste ambiente que possam contribuir com a melhoria das condições de vida dessa comunidade.

Vale frisar que o bairro apresenta problemas relacionados ao saneamento básico, infraestrutura, segurança, entre outros (DIAS, 2010), os quais estão relacionados tanto ao poder público quanto à cultura local. Assim, partiu-se da premissa de que a construção de uma proposta que aborde situações-limite desta comunidade em sala de aula, proporcionando a tomada de consciência dos educandos, poderia contribuir, dentre outros aspectos, com a melhoria das condições de vida da comunidade escolar.

Em síntese, o processo de construção das atividades foi orientado pelas seguintes etapas, as quais são descritas de forma mais detalhada em Sousa et al. (2014):

i) Aproximações iniciais com a comunidade escolar - primeiros contatos com o contexto escolar, em particular com as professoras, para discussão das possibilidades de trabalho em conjunto. Após um levantamento, realizado pelos integrantes do GEATEC, de informações sobre o bairro através de fontes secundárias, também houve a seleção, junto com as professoras, da hipótese de situação-limite "Água: abastecimento e consumo acrítico".

ii) Apresentação de possíveis situações-limite para a comunidade local - realização de uma visita à comunidade para verificação da hipótese de situação-limite, em que foram identificados novos elementos relacionados com a problemática em questão.

iii) Legitimação da hipótese - apresentação dos resultados da visita de campo para as professoras, a partir da qual foi identificada a real situação-limite, relacionada ao fato de a comunidade ter que recorrer a diferentes meios de obtenção de água para suprir as suas necessidades básicas. Com isso, organizou-se o tema "Consumo de água

\footnotetext{
${ }^{5}$ As atividades complementares referem-se ao momento de planejamento e organização das aulas realizado pelos professores na escola, as quais ocorrem uma vez por semana.
} 
na comunidade do Banco da Vitória" e o Contratema (SILVA, 2004) "Consumo consciente da água", que sintetiza a visão das educadoras sobre o tema. Destaca-se que a legitimação da hipótese de situação-limite foi realizada tanto com os moradores, durante a visita, quanto com a discussão das informações obtidas junto às professoras. Isto porque as professoras, além de constituírem representantes da comunidade local, uma vez que lecionam na escola há anos e uma delas reside no bairro Banco da Vitória, enriqueceram as informações obtidas durante a visita com algumas questões socioeconômicas e culturais implícitas nas falas dos moradores relacionadas ao consumo acrítico da água.

iv) Organização da Programação Curricular - Estruturação da proposta em quatro unidades, representativas das fontes de água existentes no bairro: Água da Bica; Água do Rio; Água do Poço, Água da EMBASA ${ }^{6}$. Seleção de conceitos e conteúdos de Física, Química, Biologia e Matemática, necessários para compreensão do tema, tais como: densidade, tipos de água (destilada, mineral, etc.), tratamento da água, doenças causadas por água contaminada, poluição, consumo consciente, desperdício etc., e construção das atividades didático-pedagógicas em conjunto com as professoras.

Tais etapas apresentam aspectos tanto da Abordagem Temática Freireana, quanto da Práxis Curricular via Tema Gerador, os quais são discutidos por Sousa et al. (2014), constituindo a investigação do tema de maneira auto-organizada e organicamente relacionada ao contexto escolar.

Uma vez que o processo de obtenção do tema e a construção das atividades foi realizado em conjunto com as professoras, considerou-se importante compreender as dificuldades e contribuições identificadas pelas mesmas, acerca do processo de obtenção do Tema Gerador e à interação com o grupo de estudos.

Nesse sentido, para investigar tais aspectos foram utilizados como instrumentos para obtenção de informações um diário reflexivo, adaptado de Pórlan e Martín (1997), em que foram realizados registros de cada reunião pelos membros do GEATEC, e entrevistas semiestruturadas ${ }^{7}$ (TRIVIÑOS, 1987) realizadas com as professoras da escola, as quais foram orientadas pelas seguintes questões:

\footnotetext{
${ }^{6}$ Empresa Baiana de Água e Saneamento S.A.

${ }^{7}$ As questões norteadoras da entrevista semiestruturada foram aprovadas pelo Comitê de Ética em Pesquisa com Seres Humanos da UESC (CAAE: 17530513.3.0000.5526).
} 
Quadro 1 - Questões norteadores da entrevista semiestruturada

1. Quais as dificuldades encontradas no processo de elaboração da proposta em conjunto com o grupo de estudos da UESC sobre o tema "Consumo de água na comunidade do Banco da Vitória"?

2. Quais os aspectos positivos e/ou negativos do trabalho em conjunto com o GEATEC?

3. Em sua opinião, quais desafios poderão ser encontrados durante a implementação das atividades elaboradas sobre o tema "Consumo de água na comunidade do Banco da Vitória"?

4. Quais as suas expectativas no que tange ao envolvimento dos estudantes durante a implementação das atividades?

5. Possui alguma sugestão para as parcerias entre grupos de pesquisa/estudos da universidade com professores da educação básica?

Fonte: Os autores.

A utilização do diário reflexivo foi importante tanto para a reorientação das ações desenvolvidas junto às professoras na construção das atividades didáticopedagógicas, quanto para a elaboração de questões norteadoras e estabelecimento do rapport na entrevista. Isto porque, o diário permite o desenvolvimento de focalizações sucessivas e reflexivas sobre as situações vivenciadas, favorecendo o desenvolvimento da pesquisa (PORLÁN; MARTÍN, 1997).

Nesse sentido, a análise do diário reflexivo foi realizada tendo em vista identificar, a partir das ações desenvolvidas, elementos significativos que poderiam ser melhor compreendidos por meio da entrevista. Com isso, as informações obtidas a partir do diário sinalizaram para a necessidade de investigar as percepções das professoras sobre o desenvolvimento de uma proposta com base na perspectiva freireana e da parceria com o GEATEC, orientando a construção das questões norteadores da entrevista.

A opção pela entrevista semiestruturada justifica-se, especialmente, por valorizar a presença do investigador ao tempo em que oferece oportunidades para o entrevistado alcançar a liberdade e a espontaneidade necessárias para a pesquisa (TRIVIÑOS, 1987). Além disso, a entrevista proporciona o caráter dialógico necessário para o fortalecimento da relação de confiança e a harmonia entre os sujeitos, imprescindível frente às incertezas que permeiam o início da entrevista, como sinalizado por Triviños (1987). Assim, coerentes com a proposta da entrevista semiestruturada, as questões elaboradas partiram de questionamentos básicos, apoiados em hipóteses balizadas pelo objetivo da pesquisa, contribuindo com o surgimento de novas questões à medida que as respostas eram fornecidas pelas professoras. 
Vale ressaltar, ainda, que embora três professoras tenham participado do processo de construção e implementação das atividades, a entrevista só foi realizada com duas delas, uma vez que a terceira professora reside em município vizinho e não foi possível estabelecer um horário e local apropriados para a entrevista.

As informações obtidas nas entrevistas foram analisadas por meio da Análise Textual Discursiva (ATD) (MORAES; GALIAZZI, 2007), a qual tem sido utilizada como uma ferramenta metodológica em diversos estudos da área de Educação em Ciências (CARAMELLO et al., 2014; OLIVEIRA; LANGHI, 2014; SOLINO; GEHLEN, 2014; GIACOMINI; MUENCHEN, 2015).

Sendo assim, após a transcrição das entrevistas, houve a desconstrução das informações, fragmentando-as em unidades de significado (Unitarização - $1^{\text {a }}$ etapa da ATD) e agrupando-as segundo suas semelhanças semânticas, produzindo as categorias: Condições para o planejamento e implementação da proposta baseada em Tema Gerador e Parceria universidade-escola (Categorização - $2^{\mathrm{a}}$ etapa da ATD), bem como a discussão das categorias a partir da elaboração de textos descritivos e interpretativos (Comunicação - $3^{\mathrm{a}}$ etapa da ATD).

Com isso, foi possível identificar aspectos relacionados às dificuldades e às contribuições constatadas pelas professoras ao organizar o currículo a partir de um Tema Gerador e desenvolver propostas diferenciadas em parceria com um grupo da universidade. Destaca-se que a identificação das professoras é realizada por meio das expressões P1 e P2, resguardando-se a identidade das mesmas, durante a entrevista.

\section{Condições para o planejamento e implementação da proposta baseada em tema gerador}

Segundo Halmenschlager et al. (2013), o processo de construção e implementação de propostas com base em temas constitui espaço de formação permanente para os professores da educação básica. Isto é, diferentemente de processos formativos centrados na transmissão de receitas, a formação permanente envolve o professor em um processo de reflexão acerca da realidade em que atua e sobre seu fazer docente, sinalizando para os problemas enfrentados e para as possibilidades de mudança a partir da reorientação da prática pedagógica vigente.

Os autores também salientam que são encontradas diversas dificuldades para efetivação de propostas baseadas em temas, tais como: romper com a lógica de ensino tradicional; estabelecer maior articulação entre tema e conteúdo; falta de material 
didático; definir critérios de seleção dos temas; criar espaços e tempos para discussões; e ainda, a estrutura segmentada dos cursos de graduação. Embora Halmenschlager et al. (2013) não explicitem o que compreendem por ensino tradicional, subentende-se que, fundamentados na perspectiva freireana, estejam considerando este tipo de ensino como aquele baseado na educação bancária (FREIRE, 1987), em que o professor atua como detentor do conhecimento, ignorando as experiências e realidades dos educandos.

Nesse sentido, ainda que as professoras entrevistadas na presente pesquisa estivessem abertas ao diálogo, também revelaram ter enfrentado algumas das dificuldades apontadas por Halmenschlager et al. (2013) durante o processo de construção do tema "Consumo de água na comunidade do Banco da Vitória", tais como a rotina escolar e docente, a falta de material didático e a falta de espaços e tempos para planejamento de atividades diferenciadas. No que concerne à falta de material, por exemplo, a professora P1 aponta que:

Mas, o que a gente sente dificuldade é a questão de materiais, da própria estrutura escolar que não favoreceu, as paradas ${ }^{8}$, que foram constantes (P1).

É importante destacar a relação entre a falta de materiais e a estrutura física da Escola Municipal do Banco da Vitória. Dividida em uma sede e um anexo, separados pela Rodovia Jorge Amado, a escola tem sua estrutura fragmentada. Embora não tenha laboratório de ciências, a escola conta com um laboratório de informática que fica localizado na sede, sendo necessário que os professores atravessem a rodovia junto com os estudantes para ministrar aulas que utilizem recursos digitais. Os riscos envolvidos nesta prática inibem o desenvolvimento de atividades do gênero, restringindo ainda mais os recursos da escola.

No que se refere à questão da falta de tempo, destaca-se que a mesma foi mencionada pelas professoras com diferentes enfoques. Um deles está relacionado ao desenvolvimento das etapas de Investigação Temática, como evidencia o excerto a seguir:

[...] pra nós, enquanto professores de sala de aula, do dia-a-dia, não é fácil fazer aquele tipo de proposta de trabalho. De você pesquisar um assunto e depois ir trabalhar aquele assunto, começou desde a comunidade, da pesquisa de vocês, nós não teríamos tempo. Seria mentira eu dizer isso, mentira, não tem como fazer um tipo de trabalho daquele. (P2)

Dificuldades ligadas à compatibilização entre o tempo escolar e o trabalho com temas também foram identificados por Muenchen e Auler (2007). Estes autores

\footnotetext{
8 Durante o período de elaboração das atividades, as escolas do município realizaram diversas paralisações em suas atividades para reivindicar melhores condições de trabalho, salário etc.
} 
analisaram o envolvimento de professores no desenvolvimento de temas baseados numa articulação entre o referencial freireano e o enfoque das relações entre Ciência, Tecnologia e Sociedade. Muenchen e Auler (2007) identificaram que, embora o viés interdisciplinar seja essencial para compreensão de situações reais, o seu desenvolvimento requer disponibilidade temporal para o planejamento coletivo. De acordo com os autores, ainda que alguns professores tenham interesse em trabalhar com temas, a falta de tempo dificulta a articulação entre seus pares e a promoção de um trabalho interdisciplinar.

Por outro lado, ainda que a professora P2 tenha apresentado uma visão pessimista em relação ao tempo disponível para realizar uma pesquisa junto à comunidade, mencionou a experiência de outro professor da escola que teria feito um trabalho semelhante.

Tivemos um colega que ele fez, ele é professor de história, e ele foi pra comunidade, mas ele fazia isso no turno oposto, que ele só tem vinte horas. [...] Quem trabalha sessenta horas, quarenta horas, não tá disponível na escola no outro turno só para um tipo de trabalho assim, de conhecer a comunidade. (P2)

A professora P2 relaciona, portanto, a sua dificuldade em realizar uma pesquisa junto à comunidade ao fato de trabalhar em mais de uma escola, possuindo uma carga horária de trabalho excessiva. Tal aspecto também é mencionado por ela quando discutido o tempo das reuniões com os integrantes do GEATEC, segundo a professora:

Porque a gente tem que ter o momento no AC [Atividades Complementares], fica tipo assim 15 em 15 dias, uma vez por mês, pra gente tá se reunindo. Porque a gente precisa também falar de nossas atividades na escola, então muitas reuniões acabam também atrapalhando. (P2)

De acordo com P2, as constantes reuniões junto ao GEATEC podem atrapalhar o desenvolvimento das atividades na escola, visto que são realizadas durante o período que as professoras utilizam para o seu planejamento. A partir desta fala, há indicativos de que, embora as atividades estivessem sendo elaboradas para implementação na escola, P2 as compreende como algo complementar.

A dificuldade das professoras compreenderem o processo de construção das atividades como uma atividade formativa, que integra o fazer docente, pode estar relacionada à ausência de ações desta natureza no contexto em que atuam. Durante as reuniões as professoras relataram, por exemplo, a participação em processos formativos, muitas vezes, desenvolvidos pela secretaria de educação do município ou do estado da Bahia, apenas com a finalidade de atualizar os docentes quanto às diferentes estratégias 
didático-pedagógicas existentes. Tais abordagens, em geral, alheias à realidade escolar, contribuem com uma visão da formação de professores como orientada pela transmissão de conteúdos e que não considera o professor enquanto sujeito da própria prática.

Destaca-se, contudo, que o desenvolvimento de processos formativos no contexto escolar, tal como destacado por Freire (2006), favorecem o desenvolvimento da formação constante e sistematizada do professor, assim como com a ação-reflexãoação dos educadores e o reconhecimento/desenvolvimento da autonomia docente.

Quanto ao desenvolvimento das etapas da Investigação Temática, em especial, do Levantamento Preliminar, as professoras apresentam outro desafio:

Então a gente tem um pouco de dificuldade de chegar até eles [comunidade], a gente tem que conversar, eles são desconfiados. (P1)

A gente acaba indo dar aula, conhece o aluno naquele instante ali e pronto, não dá tempo não. Eu acho que o fator maior da gente enquanto professor hoje é ter tempo pra se dedicar aquela escola, e você sabe que a gente não trabalha só em uma escola. (P2)

Enquanto P2 menciona, novamente, a falta de tempo para a aproximação com a comunidade local, sinalizando para o distanciamento entre professor e aluno existente em sua prática pedagógica, P1 destaca a dificuldade de estabelecer uma relação de confiança para se comunicar com os moradores locais, possivelmente relacionado ao fato de não residir na comunidade. Também por esta razão o GEATEC contou com a colaboração de moradores locais para auxiliar na visita, conforme proposto por Freire (2011), contribuindo com o processo de aproximação com a comunidade.

Ainda com relação à questão temporal, P2 faz referência à falta de tempo em sala de aula para desenvolver atividades diferenciadas:

Agora, o ponto negativo que eu achei é o tempo da gente, enquanto em sala de aula.[...] Quando você arrumou o material, quase que a aula já acabou. (P2)

Muitos estudantes desta instituição moram em localidades distantes, na zona rural e em distritos vizinhos. Assim, a falta e atraso, recorrentes, do transporte e merenda escolar geravam como consequências dias não letivos e a diminuição da duração das aulas para 40 minutos. O que prejudicava o desenvolvimento de atividades mais elaboradas e que requerem mais tempo de sala de aula. No que concerne ao desenvolvimento de atividades experimentais, durante o desenvolvimento do Tema Gerador "Consumo de água na comunidade do Banco da Vitória", por exemplo, as professoras sinalizam para o desafio de preparar os materiais e realizar a atividade no pouco tempo de aula. Tais aspectos requerem novas concepções de ensino, para que 
toda escola se reestruture e o professor tenha um tempo destinado para o planejamento de atividades didático-pedagógicas, conforme apontam Delizoicov et al. (2011).

A dificuldade em estabelecer horários para o planejamento também foi relacionada por P2 ao número de turmas em que atua, segundo a professora:

[...] pra uma escola de primeira à quarta séria, como vocês já tinham feito antes, talvez o resultado seja muito melhor, porque é um grupo menor. Mas na nossa realidade de professor com várias turmas é um trabalho mais difícil [...] O tempo é o nosso maior vilão. Não tinha jeito. Quando você tem uma diversidade de turmas muito grandes [...] são programas diferentes pra você tá adequando aquele tema. (P2)

Fazendo referência ao desenvolvimento do tema "Rio Cachoeira: que água é essa?" (SOLINO, 2013), realizado com a colaboração do GEATEC numa turma do $5^{\circ}$ ano do Ensino Fundamental e apresentado às professoras durante as reuniões, P2 denota que, ao contrário deste nível de ensino, em que cada professor é responsável por uma única turma, abordar Temas Geradores no contexto em que atua e adaptá-los para diferentes turmas é um desafio. Por outro lado, P1, que não ministra aulas no $6^{\circ}$ ano do Ensino Fundamental, participou da elaboração da proposta adaptando as atividades elaboradas para sua prática pedagógica, como apresenta a fala seguinte:

\begin{abstract}
[...] eu trabalhei de modo mais específico na minha área, densidade, flutuação, a questão no caso do "flutua e afunda", também foi interessante porque a gente viu isso na sala de aula. Nós trabalhamos em parceria com os meninos que estavam estagiando na minha sala e a gente falou de empuxo, a gente falou de força, a gente falou então de peso, foi mais voltado pra minha área. (P1)
\end{abstract}

P1, enquanto professora de ciências do $9^{\circ}$ ano do Ensino Fundamental, aprofundou as discussões junto ao grupo em sala de aula, enfatizando conceitos de Física e desenvolvendo algumas atividades no contexto em que atua. Com isso, há indicativos na fala de P1 que apesar da dificuldade discutida por P2, parcerias entre os próprios professores da escola podem amenizá-las, e que o trabalho coletivo pode auxiliar o planejamento a partir de um Tema Gerador para diferentes turmas.

Quanto ao posicionamento das professoras diante do trabalho com temas na escola, P2 apresenta algumas perspectivas futuras:

Você parte do tema, o tema gerador de todo o assunto que vai puxando e que a gente não aprendeu isso, fazer assim. Isso é interessante, então é uma maneira. Foi um jeito interessante de trabalhar o assunto que até então eu não sabia, não tinha feito, partir de um tema. Vamos ver se a gente vai conseguir fazer isso o ano que vem, partir de um tema pra construir um tipo de atividade, como foi essa que vocês construíram conosco. Eu achei interessante, vamos ver se a gente vai conseguir. Porque eu e P3 e P1, a gente trabalha sempre muito juntas. A gente sempre tá perto uma da outra desde 
que começamos a trabalhar aqui na escola. Então isso, com a gente, eu acho que isso vai ser possível, vamos ver aí, né? (P2)

Constata-se que, apesar das dificuldades encontradas durante o processo de construção e implementação de algumas atividades, P2 se interessou pela proposta e considera a possibilidade de desenvolver um trabalho nesta perspectiva futuramente. Em especial, P2 destaca a importância do trabalho docente em equipe para a efetivação da proposta na escola. Sobre este aspecto, Freire (2006) ressalta a importância da coletividade no processo de desenvolvimento da programação curricular, salientando a formação docente no âmbito da própria escola por meio de grupos de educadores ou grupos ampliados através da articulação entre escolas próximas. Segundo Lambach (2013), uma formação de professores numa concepção crítica, que tenha por finalidade desenvolver a problematização da práxis docente só pode ocorrer coletivamente, pois sozinho o professor não consegue vislumbrar outros horizontes.

Portanto, a dificuldade apresentada pelas professoras, de realizar a Investigação Temática, bem como de elaborar um programa escolar a partir de Temas Geradores, que abarque os diferentes contextos das turmas escolares, pode ser amenizada com o envolvimento dos professores da escola no desenvolvimento da proposta, com um maior diálogo entre os educadores. Muenchen e Auler (2007) destacam que tais questões estruturais indicam a necessidade de valorização do educador, não apenas do ponto de vista do incentivo salarial, mas também para a disponibilidade de tempo para planejar e se aperfeiçoar.

P2 apresenta, ainda, outra dificuldade relacionada à abordagem de um Tema Gerador em sala de aula, que concerne às especificidades de cada turma e ao interesse dos educandos, segundo a professora:

\footnotetext{
Infelizmente os mais velhos não se interessaram, tavam lá por obrigação. Mas foi bem aceito na quinta série, na sexta série... [...] os meninos menores, os mais jovens se interessaram mais, mas os mais velhos ainda não é o que eles querem. Não atingi os mais velhos, não. Quinze, dezesseis anos na quinta série. Pra eles, não interessou nada. (P2)
}

De acordo com P2, a escola apresenta turmas do $6^{\circ}$ ano com estudantes acima da faixa etária comumente encontrada neste nível. Assim, embora as atividades tenham sido elaboradas para o $6^{\circ}$ ano, segundo o olhar da professora, não estiveram adequadas para estas turmas, que apresentaram resistência à proposta. Para o desenvolvimento de propostas futuras é relevante, portanto, investigar junto aos professores a causa dessa resistência dos alunos, a qual pode não estar somente atrelada aos aspectos que 
envolvem os interesses e necessidades dos educandos, uma vez que tais elementos foram levados em consideração no planejamento das atividades.

Apesar das dificuldades apontadas, no que se refere ao trabalho a partir de um Tema Gerador, as professoras destacam também as contribuições desta perspectiva para formação dos educandos.

[...] eles [alunos] vão ter um novo olhar. Mas como também na comunidade onde eles vivem. Porque aí eles vão estar levando informações que eles adquiriam lá na escola com a participação dos grupos, com construção de materiais, como a mosquitoeira ${ }^{9}$. Então eles vão levar isso pra comunidade, de certa forma eles vão estar aproveitando o conhecimento que eles adquiriram na escola na comunidade. (P2)

[...] a contribuição mesmo, eu acho que é a questão da conscientização, não só da comunidade escolar, como eu te falei, como da sociedade geral. (P1)

As falas das professoras denotam que a abordagem de um tema vinculado a uma situação-problema da comunidade local contribui não apenas com a apreensão de conhecimentos científicos, mas também com a construção de conhecimentos relacionados ao mundo vivencial dos estudantes e que serão explorados fora do contexto escolar.

A extrapolação dos conhecimentos escolares para a realidade dos educandos apontada pelas professoras está em sintonia com os pressupostos freireanos de educação. Ao compreender a educação como uma forma de intervenção no mundo, Freire (2011) propõe uma educação de caráter reflexivo que implica um constante ato de desvelamento da realidade, resultando na compreensão crítica do indivíduo sobre o seu entorno. Nessa perspectiva, os conhecimentos científicos passam a ter uma finalidade que transcende sua aplicação em exames avaliativos, por exemplo, tornandose instrumento para compreensão crítica da realidade. É nesse sentido que Freire defende a ideia da educação libertadora, na qual, a partir do reconhecimento crítico da situação opressora em que o indivíduo se encontra e por meio de uma ação transformadora que incida sobre ela, possa ser instaurada a busca do "ser mais", enquanto processo de humanização dos homens.

Quanto à abordagem de conhecimentos de Física e Química no Ensino Fundamental II, P2 complementa:

\footnotetext{
9 Armadilha para prender e matar o mosquito transmissor da dengue. A construção da mosquitoeira é apresentada como uma das atividades da proposta didático-pedagógica elaborada. Informações mais detalhadas estão em: https://www.youtube.com/watch?v=B_Bwo8vYnVY https://www.youtube.com/watch?v=8BfQXHVofBE
} 
[...] a gente não tinha dado o conceito de densidade e tudo, como tá no início, eu não sei se ficou... Com o fato daquela [atividade] ${ }^{10}$ flutua e afunda foi interessante. Mas ainda lá na quinta série, lá pra eles, ainda não tá tão palpável. Mas já começou a despertar. (P2)

Ainda que a fala de P2 não seja suficientemente clara quanto à compreensão dos educandos sobre conceitos de Física e Química, há indicativos de que o trabalho com esses conceitos, para a professora, constitui ponto de partida para a aprendizagem dos alunos.

Segundo Gehlen et al. (2012), a inserção de palavras representativas de um conceito permite a construção dos seus primeiros sentidos, a apreensão de novos significados à palavra. Assim, embora os educandos, neste momento, possam não apresentar uma visão sistematizada do conhecimento científico será em torno da palavra que o conceito irá se desenvolver, possibilitando que o sujeito utilize-o em diversas situações da sua realidade. Em outros termos, há possibilidade tanto do desenvolvimento do conceito científico, ainda que de forma inicial, quanto da apreensão da palavra no seu contexto de uso, na vivência do sujeito. Afinal, a palavra na perspectiva freireana também pode representar conhecimentos historicamente construídos que serão apreendidos pelo educando (GEHLEN, 2009).

Nesse contexto, as entrevistas sinalizam que as dificuldades encontradas pelas professoras da educação básica ao trabalhar com Temas Geradores estão relacionadas principalmente com as condições de trabalho das professoras. As dificuldades relacionadas à estrutura física da escola, às especificidades das turmas, aos tempos e espaços para planejamento e à carga horária excessiva de trabalho foram salientadas através das percepções das professoras.

\section{Parceria universidade-escola}

De acordo com Zanon et al. (2012), é preciso estabelecer parcerias entre a comunidade acadêmica e escolar, que permitam refletir em torno do distanciamento da pesquisa e do ensino, uma vez que as contribuições da pesquisa dificilmente serão concretizadas sem que sejam discutidas na formação inicial e continuada de professores. Assim, nesta categoria, são discutidas as colocações das professoras que dizem respeito às

\footnotetext{
${ }^{10}$ Neste momento a professora faz referência a uma das atividades que integram o planejamento do tema "Consumo de água na comunidade do Banco da Vitória". Especificamente, menciona a adaptação de uma atividade extraída do livro: SCHIEL, D.; ORLANDI, A. S (org). Ensino de Ciências por investigação. Centro de Divulgação Científica e Cultural. USP, 2009.
} 
contribuições da parceria da escola com o grupo de estudos da universidade e algumas reflexões em torno da aproximação entre pesquisa e ensino.

Ao tratar das contribuições do trabalho em conjunto com o GEATEC, as professoras destacam que o contato com o grupo trouxe novas ideias e propostas para a escola:

[...] vêm ideias novas, pensamentos novos... [...] contribuiu de forma lúdica, porque nós trabalhamos com algumas experiências, mas voltada, como eu te falei, para o conteúdo de Química e Física, que é mais interessante pra mim. (P1-grifo nosso)

[...] a equipe sempre trouxe muitas ideias novas e quase que a colaboração da gente, eu acho sinceramente que a nossa colaboração foi até pequena, não achei assim tão grande. [...] Uma coisa que vocês têm que a gente não tem, material. E que vocês também disponibilizaram pra gente. A gente não tem, não tem material. Então isso já ajuda. (P2-grifo nosso)

A colaboração com o GEATEC aproximou os resultados das pesquisas e novas estratégias didáticas, as denominadas "ideias novas", das professoras, que em função das condições estruturais de trabalho e de carreira, muitas vezes, não conseguem se atualizar, conforme indica a fala a seguir:

E também às vezes ideias que a gente não tinha, né, vocês levaram pra gente. Naquele corre, no dia-a-dia, a gente acaba bitolado num assunto só e esquece de ir pra outros lugares. (P2)

Esta fala de P2 indica as contribuições da interação das professoras da escola com o grupo de estudos da universidade, composto por professores formadores, graduandos e mestrandos, para a sua formação. Isto é, revela a importância das interações entre sujeitos com diferentes vivências formativas e conhecimentos diversificados para o desenvolvimento e enriquecimento das atividades (ZANON et al., 2012).

Além disso, segundo P2 a parceria com o GEATEC “Contribui nas nossas práticas, a gente vai reavaliar as nossas práticas." (P2). O que vai ao encontro do trabalho de Halmenschlager et al. (2011), que discute a possibilidade de que processos de reconstrução curricular como esse, vinculados ao contexto escolar, se configurarem como espaço para repensar a prática com vistas à melhoria do ensino.

Ainda com relação à participação do GEATEC na construção das atividades, a partir de um Tema Gerador, P2 enfatiza que:

Pra gente fazer sozinho não daria, não teríamos feito não. Se não fosse vocês não teria acontecido. É um projeto interessante da universidade? É. Mas eu ainda repito, para as escolas de base, lá do ensino fundamental I e não do fundamental II, onde a gente tá trocando de salas. (P2) 
Com relação à implementação das atividades em sala de aula, as professoras mencionam as contribuições do trabalho em parceria com grupos da universidade quanto ao envolvimento dos estudantes:

Vai contribuir na questão da aprendizagem do aluno, porque, como eu falei pra você, vem pessoas de fora, então eles tão acostumados com a gente e quando vem alguém de fora é mais interessante pra eles. (P1)

É importante destacar que o termo "pessoas de fora" utilizado por P1 faz referência a presença de estagiários ${ }^{11}$, estudantes do curso de Licenciatura em Física da UESC, que estavam acompanhando, para cumprir requisitos do curso de graduação, o desenvolvimento da disciplina de Ciências no $9^{\circ}$ ano durante este período. Já P2 destaca a importância da participação de integrantes do grupo de estudos durante o desenvolvimento das aulas.

De repente isso aí era interessante, vocês fazerem algumas atividades pra eles verem que não é a gente que tá fazendo. (P2-grifo nosso)

De acordo com as professoras, os estudantes costumam se interessar mais pelas aulas quando são realizadas palestras e atividades por profissionais que não atuam na escola, conforme a fala de P1: "eles tão acostumados com a gente e quando vem alguém de fora é mais interessante pra eles". Este aspecto também foi mencionado pelas professoras durante as reuniões, especialmente quando foi discutida a possibilidade de trazer um palestrante da empresa responsável pelo tratamento da água no município para explicar o funcionamento de uma Estação de Tratamento de Água. Tal interesse dos estudantes pode estar relacionado à mudança na rotina de sala de aula, como apresenta P1.

Além do envolvimento de integrantes do GEATEC, no desenvolvimento de algumas atividades, as professoras apontaram mais algumas sugestões para trabalhos futuros:

Então eu acho assim, pra um futuro que a gente faça de novo, juntos isso, eu não sei, é que a gente faça no segundo semestre, onde o horário já esteja organizado. Porque no primeiro semestre eu não quero, não tem como, você viu que loucura. (P2)

\footnotetext{
11 Durante o período de construção das atividades didático-pedagógicas a partir do tema "Consumo de água na comunidade do Banco da Vitória" duas das professoras estavam supervisionando estagiários do curso de Licenciatura em Física da UESC que ministravam aulas de Ciências numa turma no $9^{\circ}$ ano e do $6^{\circ}$ ano do Ensino Fundamental. Por isso, em alguns momentos a professora P1 contou com a colaboração dos estagiários para o desenvolvimento das atividades, ainda que os mesmos não estivessem envolvidos no trabalho em questão.
} 
A colocação de P2 está relacionada às constantes mudanças de horário das aulas na escola que atrapalharam os encontros junto ao GEATEC. De acordo com a professora, problemas como estes não são comuns, mas têm maior probabilidade de acontecerem no primeiro semestre do ano letivo. Assim, uma forma de organizar melhor as reuniões, e consequentemente o planejamento, seria instituindo a parceria no segundo semestre.

Ao discutir a parceria entre grupos da universidade e professores da educação básica, P1 compara a postura dos pesquisadores atualmente com o tempo em que cursava sua graduação:

Vocês tão mais próximos, coisa que não se tinha antigamente. Então a gente estudava e ia pro mercado de trabalho. Hoje em dia eu acho que a UESC ela se aproximou das comunidades. E isso é importante. É um retorno que a universidade está dando às comunidades próximas a ela. (P1-grifo nosso)

Com isso, P1 sinaliza que a aproximação das ações desenvolvidas pela UESC e o contexto escolar tem avançado, que existe um esforço por parte da universidade em promover uma aproximação dos resultados das pesquisas para sala de aula. Para Torres et al. (2008), há a necessidade dos pesquisadores estabeleceram cada vez mais parcerias entre universidade e escola, em particular quando garantidas pelas políticas públicas, quando se pretende contribuir com ações no âmbito da escola.

No mesmo sentido, Lambach (2013) esclarece que o desenvolvimento de uma formação permanente na perspectiva freireana não pode ser assumida sem a participação das universidades, principalmente, em função do aprofundamento teórico necessário. Segundo o autor, uma possibilidade de estreitar as relações entre as universidades e as escolas é através da extensão. Sob este prisma, convém destacar as iniciativas desenvolvidas no âmbito do Programa Institucional de Bolsas de Iniciação à Docência, tal como representado pelo trabalho de Furlan et al. (2011), e no contexto do GEATEC, que tem realizado processos formativos em parceria com professores de escola e secretarias de educação de modo sistemático, tal como apresentado por Magalhães et al. (2015) e Novais et al. (2015).

Para Freire (2006), o intercâmbio entre universidade e escola é saudável e favorece ambos os contextos. Para o autor, além da universidade ter a responsabilidade social de contribuir com, entre outros aspectos, a formação dos profissionais que atuam nas redes de ensino, essa aproximação "permite que a própria universidade se aproprie de um conhecimento da realidade que a fará repensar o seu ensino e a sua pesquisa” (p.82). 
Preocupada com a dicotomia entre as pesquisas em ensino de Ciências e o ensino de Ciências, P1 complementa:

\begin{abstract}
Só vai dar certo, essa parceria, se, como eu tô dizendo, tiver o retorno. Porque muitos dos estudantes da UESC fazem suas pesquisas depois não retornam as comunidades pra dar um retorno do seu trabalho. Eu acho interessante trabalhar e fazer as suas conclusões e depois retornar a essa comunidade pra prestar uma satisfação do trabalho que foi feito. (P1)
\end{abstract}

A concepção de P1 aproxima-se das discussões realizadas por Delizoicov (2005, p. 369), segundo o qual "é preciso que se considere qual é a contribuição que pesquisadores em EC [Ensino de Ciências] poderão dar para potencializar o retorno dos resultados das pesquisas para o ensino de EC nas redes de ensino do país". Na perspectiva deste autor, é por meio de uma formação continuada pautada na dialogicidade e na problematização que será possível identificar e problematizar obstáculos da realidade escolar para implantação de práticas pedagógicas consoantes com as pesquisas. Nesse sentido, Halmenschlager et a. (2013) sugerem que:

O desenvolvimento de projetos na escola e a reestruturação curricular
contribuem para que ocorra a teorização da prática do professor e a produção
de novos conhecimentos acerca da mesma. Esse contexto de interação
permite ainda a socialização dos resultados das pesquisas em ensino de
Ciências, podendo promover uma maior aproximação entre a pesquisa e o
ensino de Ciências. Sob essa perspectiva, a elaboração e implementação de
práticas pautadas na abordagem de temas também contribui para que os
professores da educação básica e licenciandos possam ver a sala de aula
como espaço para a pesquisa. (HALMENSCHLAGER et al., 2013, p. 5)

Com isso, os autores explicitam a relevância de desenvolver trabalhos a partir de temas em parceria com professores da educação básica. P1 complementa sua colocação exemplificando a partir da construção do tema "Consumo de água na comunidade do Banco da Vitória" os desafios que se apresentam para estabelecer parcerias entre grupos de estudo da universidade e professores da educação básica:

Em termos de condições para que vocês possam trabalhar, vocês vão encontrar barreiras. Essa questão do horário, a questão do espaço físico, a questão que não tem material, a questão, né. Isso vocês vão encontrar sempre. Agora, vai ter que ser um trabalho de formiguinha mesmo. (P1)

Assim, a professora compreende que apesar da necessidade de estabelecer parcerias entre a universidade e escola, essa articulação é lenta e apresenta algumas dificuldades. Conscientes dessas dificuldades, pesquisadores têm proposto algumas medidas que podem favorecer a aproximação entre a pesquisa em Ensino de Ciências e o Ensino de Ciências. Entre elas, destaca-se o desenvolvimento de cursos de formação 
continuada de caráter interinstitucional, que envolvam vários setores da educação (secretarias, ministério, universidades, escolas) e garantam políticas públicas que contribuam com ações no âmbito das escolas (KRASILCHIK, 1987; DELIZOICOV, 2005; TORRES et al., 2008). No entanto, cabe salientar que as universidades não devem ser concebidas como entidades máximas que solucionam os problemas educacionais. $\mathrm{O}$ sentido atribuído à parceria entre universidades e escolas pressupõe questionar e desestabilizar as relações hierarquizadas, muitas vezes, estabelecidas entre pesquisadores e docentes das escolas.

\section{Considerações finais}

A presente pesquisa elencou os principais desafios e contribuições apontados por professoras do ensino fundamental de uma escola pública do município de Ilhéus-BA na construção de atividades didático-pedagógicas a partir de um Tema Gerador, realizada em conjunto com os integrantes de um grupo de estudos da UESC.

Com base na análise das entrevistas, foi possível organizar um quadro-síntese com o propósito de sistematizar os principais limites e contribuições apontados pelas professoras sobre o desenvolvimento do Tema Gerador no contexto escolar. O resumo das informações apresentadas e discutidas nas categorias: "Condições para o planejamento e implementação da proposta" e "Pareceria Universidade-Escola" pode ser visualizado no Quadro 2 a seguir. 
Quadro 2 - Limites e contribuições apresentadas pelas professoras acerca do desenvolvimento do Tema Gerador no contexto escolar.

\begin{tabular}{|c|c|c|}
\hline CATEGORIAS & LIMITES & CONTRIBUIÇÕES \\
\hline $\begin{array}{l}\text { Condições para o } \\
\text { planejamento e } \\
\text { implementação da } \\
\text { proposta }\end{array}$ & $\begin{array}{l}\text { - Falta de tempo para planejar atividades } \\
\text { e investigar o tema junto à comunidade; } \\
\text {-Dificuldade de entrosamento e } \\
\text { aproximação com a comunidade local; } \\
\text {-Dificuldades para implementar as } \\
\text { atividades experimentais, devido à falta } \\
\text { de condições para preparar o material e a } \\
\text { redução de horário das aulas; } \\
\text {-Dificuldade para abordar o tema e } \\
\text { adaptar as atividades para diferentes } \\
\text { turmas do ensino fundamental devido a } \\
\text { falta de tempo para replanejar, o que } \\
\text { ocasionou a falta de interesse dos alunos } \\
\text { mais velhos em relação às atividades } \\
\text { trabalhadas. }\end{array}$ & $\begin{array}{l}\text {-Percepção das atividades realizadas junto } \\
\text { ao grupo GEATEC como algo importante e } \\
\text { complementar às suas atividades escolares; } \\
\text {-Contribuição das parcerias com outros } \\
\text { professores para o planejamento e } \\
\text { implementação de atividades baseadas no } \\
\text { tema; } \\
\text {-Contribuição do tema gerador para formar } \\
\text { alunos mais conscientes dos problemas da } \\
\text { sua realidade; } \\
\text { - Compreensão de que o desenvolvimento } \\
\text { das atividades junto aos alunos possibilitou } \\
\text { o "despertar" para aprendizagem dos } \\
\text { conceitos científicos; } \\
\text { - Interesse em participar novamente de } \\
\text { trabalhos dessa natureza; }\end{array}$ \\
\hline $\begin{array}{c}\text { Parceria } \\
\text { Universidade- } \\
\text { Escola }\end{array}$ & $\begin{array}{l}\text { - Dificuldade para realizar o trabalho sem } \\
\text { o apoio do grupo; } \\
\text {-Constantes mudanças nos horários de } \\
\text { aula, que atrapalharam os encontros junto } \\
\text { ao grupo GEATEC; } \\
\text { - Pouco retorno de alguns estudantes da } \\
\text { universidade ao realizarem pesquisas nas } \\
\text { escolas; } \\
\text { - As professoras admitiram que efetivar } \\
\text { uma parceria entre universidade e escola } \\
\text { é um trabalho lento e complexo, aspecto } \\
\text { que deve ser levado em consideração. }\end{array}$ & $\begin{array}{l}\text { - As professoras ressaltaram que o contato } \\
\text { com a equipe de pesquisadores GEATEC } \\
\text { trouxe novas ideias e propostas para a } \\
\text { escola e condições materiais para a } \\
\text { implementação das atividades em sala de } \\
\text { aula; } \\
\text { - Contribuição da parceria com o GEATEC } \\
\text { para a reflexão sobre a prática; } \\
\text { - Novos aprendizados provenientes da } \\
\text { interação com o grupo GEATEC; } \\
\text {-Relevância dos trabalhos oriundos da } \\
\text { universidade, a exemplo da implementação } \\
\text { de atividades feitas por estagiários. }\end{array}$ \\
\hline
\end{tabular}

Fonte: Os autores.

Essas informações evidenciaram que as professoras encontraram diversas dificuldades na viabilização de atividades orientadas por temas, principalmente ligadas às suas condições estruturais e de carreira.

Vale salientar que as dificuldades explicitadas pelas professoras também podem ser compreendidas enquanto situações-limite que necessitam ser consideradas pelas pesquisas que se debruçam sobre processos de reorientação curricular pautados nos pressupostos freireanos. Isto é, ainda que o estudo tenha sido realizado em um contexto particular, as dificuldades constatadas pelas professoras estão em sintonia com os resultados de outros trabalhos que discutem a formação docente em uma perspectiva dialógico-problematizadora, tais como os estudos de Halmenschlager et al. (2013) e de Muenchen e Auler (2007). Por outro lado, o reconhecimento desses desafios requer uma 
reflexão crítica por parte da pesquisa acerca dos encaminhamentos que podem ser desenvolvidos para o seu enfrentamento, tendo em vista abrir caminhos para o desenvolvimento de currículos críticos na educação básica. A construção de propostas formativas pautadas nas etapas da Investigação Temática, por exemplo, podem contribuir com a identificação de possíveis situações-limite para a implementação da perspectiva freireana na escola, antecipando desafios que possam ser enfrentados e delineando encaminhamentos que possam amenizá-los durante o desenvolvimento do processo formativo, tal como sinalizado por Alves e Silva (2015).

Os resultados evidenciaram, ainda, a importância da parceria entre a escola e o grupo de estudos da universidade para a aproximação das discussões que permeiam a pesquisa em ensino de ciências do contexto escolar, assim como para a construção de um novo olhar do GEATEC sobre o cenário educacional e sociocultural da região. A formação de grupos colaborativos de pesquisa e prática, formados por integrantes da comunidade acadêmica e escolar, tem possibilitado parcerias desta natureza. Tais grupos têm sido vistos como um caminho para diminuir a lacuna entre pesquisa e prática na educação, além de ser uma forma de proporcionar a relevância e a qualidade da pesquisa educacional e de promover o desenvolvimento profissional e o empoderamento do professor (ALMEIDA et al., 2013).

Com base em Freire e Schor (1986), compreende-se que o empoderamento docente está relacionado ao desenvolvimento da consciência máxima possível ${ }^{12}$ do professor sobre a prática pedagógica vigente na escola com vistas à superação das situações-limite enfrentadas pela comunidade escolar e/ou corpo docente. Trata-se de um empoderamento que se dá por meio da interação entre os indivíduos e que se concretiza por meio da práxis.

A consolidação destes espaços evidencia, contudo, carências formativas. Grande parte do professorado apresenta dificuldades não só de pesquisar a própria prática, elemento essencial da profissão, mas também de realizar pesquisas sistematizadas. Não obstante, professores da educação básica podem apresentar vontade de desenvolver pesquisas, em especial, realizar suas pós-graduações como forma de aprimoramento profissional e de melhoria salarial. Entretanto, as condições de trabalho em que atuam

\footnotetext{
${ }^{12}$ Utilizando as categorias de análise apresentadas por Lucien Goldmann, Freire (2011) argumenta que ao nível da consciência real, o indivíduo encontra-se restrito às situações-limites, sem perceber a possibilidade de ir mais além, de atingir o "inédito viável”. Já ao atingir a consciência máxima possível, o sujeito poderá identificar o que Freire (2011) se refere como soluções praticáveis despercebidas, isto é, o caminho para superação das situações-limite vivenciadas.
} 
representa um desafio para sua aproximação desta prática. Nesse sentido, a instituição de grupos colaborativos pode contribuir com a formação permanente desses professores, garantindo o protagonismo docente na formulação e desenvolvimento de inovações educacionais.

Por outro lado, destaca-se que a implementação de temáticas que envolvam mudanças no currículo e nas relações entre educador e educando, como proposto pela Abordagem Temática Freireana e pela Práxis Curricular via Tema Gerador, necessitam de uma abertura das escolas para a mudança, oferecendo espaço e tempo para a reconstrução do currículo (HALMENSCHLAGER et al., 2011). A experiência aqui descrita indica que, embora tais aspectos sejam difíceis de serem alcançados, aproximações graduais e sucessivas com o contexto escolar são possíveis.

Além disso, é importante lembrar que no contexto da Abordagem Temática Freireana e da Práxis Curricular via Tema Gerador a mudança não é algo tratado de forma vertical em que o desejo parte de um grupo de pesquisadores, mas sim, dos sujeitos imersos naquela realidade educacional. Por isso, antes de propor transformações curriculares envolvendo toda comunidade escolar é necessário estabelecer diálogos e trocas de experiências e conhecimentos entre os integrantes da escola e grupos de universidades, a fim de consolidar parcerias mais efetivas tendo em vista a transformação colaborativa da realidade escolar, tal como realizado na etapa de Aproximação inicial com a comunidade escolar da presente pesquisa.

Por fim, é importante que pesquisas que têm como foco processos formativos de professores também tenham como objeto de estudo a interação e envolvimento de estudantes durante a implementação de atividades orientadas por temas, uma vez que é de fundamental importância compreender como e se os estudantes se apropriam de aspectos relacionados aos Temas Geradores, a exemplo de conceitos científicos e da superação de algumas situações-limite.

\section{Referências}

ALMEIDA, M. C., SEPÚlVEDA, C. A. S., EL-HANI, C. N. Colaboração entre professores de ciências e pesquisadores universitários: organização social e tensões na dinâmica de um grupo colaborativo de pesquisa. In: ENCONTRO NACIONAL DE PESQUISA EM EDUCAÇÃO EM CIÊNCIAS, 9, 2013, Águas de Lindóia-SP. Anais... Águas de Lindóia-SP. 2013.

ALVES, A. H. B.; SILVA, A. F. G. Manifestações de obstáculos gnosiológicos para a seleção de conteúdos na implementação de um currículo crítico em ciências naturais. Alexandria: Revista de Educação em Ciência e Tecnologia, v. 8, n. 1, p. 181- 
207, maio 2015. Disponível em: $<$ https://periodicos.ufsc.br/index.php/alexandria/article/view/1982-

5153.2015v8n1p181>. Acesso em: 26 abr. 2016.

CARAMELlO, G. W.; ZANOTELLO, M.; PIRES, M. O. D. C. A perspectiva freireana na formação continuada de professores de física. Alexandria: Revista de Educação em Ciência e Tecnologia, v.7, n.2, p 51-72, 2014. Disponível em: $<$ https://periodicos.ufsc.br/index.php/alexandria/article/view/38215/29119>. Acesso em: 26 abr. 2016.

DELIZOICOV, D. Resultados da pesquisa em Ensino de Ciências: comunicação ou extensão? Caderno Brasileiro de Ensino de Física, v.22, n.3, p. 364-378, 2005. Disponível em: <https://periodicos.ufsc.br/index.php/fisica/article/view/6376>. Acesso em: 26 abr. 2016.

DelizOICOV, D.; ANGOTTI, J. A. P.; PERnAMBUCO, M. M. C. A. Ensino de Ciências: Fundamentos e Métodos. São Paulo: Cortez, 2011.

DEMARTINI, G. R.; SILVA, A. F. G. Abordagem Temática na sistematização curricular para o ensino de ciências: gravidez na adolescência em uma escola estadual do município de Sorocaba-SP. In: ENCONTRO NACIONAL DE PESQUISA EM EDUCAÇÃ̃O EM CIÊNCIAS, 9, 2013, Águas de Lindóia-SP. Anais... Águas de Lindóia-SP, 2013.

DIAS, L. Avaliação Quantitativa de Sustentabilidade Comunitária - análise de Olivença, Baco da Vitória e Salobrinho, Ilhéus-Bahia. Dissertação de Mestrado em Cultura e Turismo - Universidade Estadual de Santa Cruz, Ilhéus-BA, 2010.

FREIRE, P. A Educação na Cidade. 7ª ed. São Paulo: Cortez, 2006.

FREIRE, P. Pedagogia do Oprimido. 50ª ed. Rio de Janeiro: Paz e Terra, 2011.

FREIRE, P.; SCHOR, I. Medo e ousadia: o cotidiano do professor. Rio de Janeiro: Paz e Terra, 1986.

FURLAN, A. B. S.; RICCI, E. C.; GOMES, C. G. C.; SILVA, A. F. G. Abordagem Temática no currículo de Ciências: a perspectiva ético-crítica na concepção de lixo como condição humana. In: ENCONTRO NACIONAL DE PESQUISA EM EDUCAÇÃO EM CIÊNCIAS, 8, 2011, Campinas-SP. Anais... Campinas-SP, 2011.

GEHLEN, S. T. A função do problema no processo ensino-aprendizagem de ciências: contribuições de Freire e Vygotsky. Tese de Doutorado em Educação Científica e Tecnológica - Universidade Federal de Santa Catarina, Florianópolis-SC, 2009.

GEHLEN, S. T.; DELIZOICOV, D.; MALDANER, O. A. Momentos Pedagógicos e as etapas da Situação de Estudo: complementaridades e contribuições para a Educação em Ciências. Ciências e Educação, v.18, n.1, p 1-22, 2012. Disponível em: $<$ http://www.scielo.br/scielo.php?script=sci_arttext\&pid=S1516-

$73132012000100001 \& \operatorname{lng}=\mathrm{en} \& \mathrm{nrm}=\mathrm{iso}>$. Acesso em: 26 abr. 2016. 
GIACOMINI, A.; MUENCHEN, C. Os três momentos pedagógicos como organizadores de um processo formativo: algumas reflexões. Revista Brasileira de Pesquisa em Educação em Ciências, v.15, n.2, p. 339-355, 2015. Disponível em: http://revistas.if.usp.br/rbpec/article/view/672. Acesso em: 26 Abr. 2016.

HALMENSCHLAGER, K. R.; HUNSCHE, S.; DELIZOICOV, D. Formação docente abordagem de temas: limites, potencialidades e desafios. In: SIMPÓSIO NACIONAL DE ENSINO DE FÍSICA, 20, 2013, São Paulo-SP. Anais... São Paulo-SP, 2013.

HALMENSCHLAGER, K. R.; SOUZA, C. A.; STUANI, G. M. Formação Docente no Contexto Escolar: contribuições da reconstrução curricular via Abordagem Temática. Alexandria: Revista de Educação em Ciência e Tecnologia, v.4, n.2, p. 83-107, nov 2011.

Disponível em:<https://periodicos.ufsc.br/index.php/alexandria/article/view/37561>. Acesso em: 26 abr. 2016.

KRASILCHIK, M. O professor e o currículo das ciências. São Paulo: EDUSP, 1987.

LAMBACH, M. Formação Permanente de Professores de Química da EJA na perspectiva dialógico-problematizadora freireana. Tese de Doutorado em Educação Científica e Tecnológica - Universidade Federal de Santa Catarina, Florianópolis-SC, 2013.

LIBÂNEO, J. C. Didática. São Paulo: Cortez,1990.

MAGALHÃES, R.; SOUSA, P.; NOVAIS, E.; FONSECA, K.; GEHLEN, S. A organização de atividades didático-pedagógicas de ciências baseada no Tema Gerador: "O perigo do Rio Água Preta em Pau Brsil/BA". In: SIMPÓSIO NACIONAL DE ENSINO DE FÍSICA, 21, 2015, Uberlândia-MG. Anais... Uberlândia-MG, 2015.

MORAES, R.; GALIAZZI, M. C. Análise Textual Discursiva. Ijuí: UNIJUÍ, 2007.

MUENCHEN, C.; AULER, D. Abordagem Temática: desafios na Educação de Jovens e Adultos. Revista Brasileira de Pesquisa em Educação em Ciências, v.7, n.3, 2007. Disponível em: http://revistas.if.usp.br/rbpec/article/view/61. Acesso em: 26 Abr. 2016.

NOVAIS, E.; FONSECA, K.; SOUSA, P.; MAGALHÃES, R.; SOLINO, A. P.; GEHLEN, S. O processo de Redução Temática do Tema Gerador "Para onde vai o lixo do meio rural de Iguaí/BA?". In: ENCONTRO NACIONAL DE PESQUISA EM EDUCAÇÃO EM CIÊNCIAS, 10, 2015, Águas de Lindóia-SP. Anais... Águas de Lindóia-SP, 2015.

OLIVEIRA, F. A.; LANGHI, R. Educação em Astronomia: investigando aspectos de conscientização socioambiental sobre a poluição luminosa na perspectiva da abordagem temática. Ciência \& Educação, v.20, n.3, p. 653-670, 2014. Disponível em: $<$ http://www.scielo.br/scielo.php?script=sci_arttext\&pid=S1516-

$73132014000300653 \& \operatorname{lng}=e n \& n r m=$ iso $>$. Acesso em: 26 Abr. 2016.

PORLÁN, R.; MARTÍN, J. El diario del profesor: un recurso para la investigación la aula. Sevilla: Díada, 1997. 
SILVA, A. F. G. A construção do currículo na perspectiva popular crítica: das falas significativas às práticas contextualizadas. Tese de Doutorado em Educação e Currículo - Pontifícia Universidade Católia de São Paulo, São Paulo, 2004.

SOLINO, A. P. Abordagem Temática Freireana e Ensino de Ciências por Investigação: contribuições para o Ensino de Ciências/Física nos anos iniciais. Dissertação de Mestrado em Educação Científica e Formação de Professores - Universidade Estadual do Sudoeste da Bahia, Jequié-BA, 2013.

SOLINO, A. P.; GEHLEN, S. T. A Conceituação Científica nas Relações Entre a Abordagem Temática Freireana e o Ensino de Ciências por Investigação. Alexandria: Revista de Educação em Ciência e Tecnologia, v.7, n.1, p. 75-101, 2014. Disponível: $<$ https://periodicos.ufsc.br/index.php/alexandria/article/view/38178/29108>. Acesso em: 26 abr. 2016.

SOUSA, P. S.; SOLINO, A. P.; FIGUEIREDO, P. S.; GEHLEN, S. T. Investigação Temática no Contexto do Ensino de Ciências: Relações entre a Abordagem Temática Freireana e a Práxis Curricular via Tema Gerador. Alexandria - Revista de Educação em Ciência e Tecnologia, v.7, n.2, p. 155-177, 2014. Disponível em: $<$ https://periodicos.ufsc.br/index.php/alexandria/article/view/38222>. Acesso em: 26 abr. 2016.

STUANI, G. M. A construção curricular popular crítica no ensino de ciências naturais e suas implicações na prática docente. Dissertação de mestrado em Educação Científica e Tecnológica - Universidade Federal de Santa Catarina, Florianópolis-SC, 2010.

TAVARES, S. S.; BENEDITO, G. S.; MUENCHEN, C. Armas: segurança ou insegurança?:uma experiência com o ensino de Física. In: SIMPÓSIO NACIONAL DE ENSINO DE FÍSICA, 20, 2013, São Paulo-SP. Anais... São Paulo-SP, 2013.

TORRES, J. R. Educação Ambiental Crítico-Transformadora e Abordagem Temática Freireana. Tese de Doutorado em Educação Científica e Tecnológica - Universidade Federal de Santa Catarina, Florianópolis-SC, 2010.

TORRES, J. R.; GEHLEN, S. T.; MUENCHEN, C.; GONÇALVES, F.P; LINDEMANN, R. H. GONÇALVES, F.J.F. Ressignificação curricular: contribuições da Investigação Temática e da Análise Textual Discursiva. Revista Brasileira de Pesquisa em Ensino de Ciências, v. 8, n. 2, 2008. Disponível em: http://revistas.if.usp.br/rbpec/article/view/52. Acesso em: 26 Abr. 2016.

TRIVIÑOS, A. N. A pesquisa qualitativa em educação. São Paulo: Atlas, 1987.

ZANON, L. B.; HAMES, C.; SANGIOGO, F. A. Interações em espaços de formação docente inicial na perspectiva da (re)construção do currículo escolar na modalidade de Situação de Estudo. Investigações em Ensino de Ciências, v. 17 (1), p. 21-35, 2012. Disponível em: < http://www.if.ufrgs.br/ienci/artigos/Artigo_ID277/v17_n1_a2012.pdf>. Acesso em: 26 Abr. 2016. 
POLLIANE SANTOS DE SOUSA. Graduada em Licenciatura em Física pela Universidade Estadual de Santa Cruz - UESC (2013), mestre em Educação em Ciências pela mesma universidade (2015). Doutoranda do Programa de Pós-Graduação em Educação Científica e Tecnológica pela Universidade Federal de Santa Catarina UFSC. Pesquisa na área de Educação Científica, com ênfase no Ensino de Ciências/Física e na Abordagem Temática Freireana.

ANA PAULA SOLINO BASTOS. Graduada em Pedagogia pela Universidade Estadual de Santa Cruz - UESC (2011) e mestrado em Educação em Ciências e Matemática pela Universidade Estadual do Sudoeste da Bahia - UESB (2013), Doutoranda do Programa de Pós-Graduação em Educação da Universidade de São Paulo (FEUSP). Pesquisa na área de Educação Científica, em especial nos seguintes temas: Ciências/Física nos Anos Iniciais, Abordagem Temática Freireana e Ensino de Ciências por Investigação.

PRISCILA SILVA DE FIGUEIREDO. Graduada em Licenciatura Plena em Ciências Biológicas pela Universidade Estadual do Sudoeste da Bahia - UESB, campus de Jequié (2010) e Mestre em Ensino, Filosofia e História das Ciências pela Universidade Federal da Bahia - UFBA (2013). Atualmente é professora do curso de Licenciatura em Ciências Biológicas da UESB, campus de Itapetinga. Participa do Grupo Colaborativo de Pesquisa em Ensino de Ciências (GCPEC) da Universidade Estadual de Feira de Santana (UEFS) e do grupo Colaboração em Pesquisa e Prática em Educação Científica (CoPPEC) da UFBA. Tem pesquisado a respeito das inovações educacionais no ensino de Ciências e Biologia, sobre a parceria universidade-escola e os desafios para romper com a lacuna entre a pesquisa e a prática em educação.

SIMONI TORMÖHLEN GEHLEN. Graduada em Física Licenciatura Plena pela Universidade Federal de Santa Maria (2002), mestrado em Educação nas Ciências pela Universidade Regional do Noroeste do Estado do Rio Grande do Sul - UNIJUÍ (2006) e doutorado em Educação Científica e Tecnológica pela Universidade Federal de Santa Catarina - UFSC (2009). Atualmente é professora do curso de Licenciatura em Física da Universidade Estadual de Santa Cruz - UESC e do Programa de Pós Graduação em Educação em Ciências desta universidade. Tem experiência na área de Educação, com ênfase em Ensino de Ciências/Física, atuando principalmente nos seguintes temas: Práticas Freireanas no Ensino de Ciências, aproximações entre as ideias de Lev S. Vygotsky e Paulo Freire, Situação de Estudo, Abordagem Temática Freireana.

Recebido: 28 de março de 2015

Revisado: 02 de março de 2016

Aceito: 12 de abril de 2016 